\title{
0 ensino do pensamento computacional em séries finais do ensino fundamental: uma proposta embasada na neurociências
}

\section{Douglas Furtado Felix ${ }^{1}$, Cleo Zanella Billa ${ }^{2}$ and Diana Francisca Adamatti ${ }^{1}$}

\author{
${ }^{1}$ Programa de Pós-Graduação em Modelagem Computacional da Universidade Federal do Rio Grande \\ (PPGMC/FURG) and ${ }^{2}$ Centro de Ciências Computacionais da Universidade Federal do Rio Grande (C3/FURG) \\ * \{douglasfurtadof, cleobilla, dianaada\}@gmail.com
}

Recebido: 05/02/2019. Revisado: 08/02/2019. Aceito: 01/03/2019.

\begin{abstract}
Resumo
É de tamanha relevância pesquisar acerca do pensamento computacional e suas possíveis alterações fisiológicas no cérebro de estudantes do ensino fundamental. Este artigo apresenta um recorte dos dados coletados de uma pesquisa que pretende identificar as áreas do cérebro que são ativadas antes e depois de um curso de aprendizado de lógica computacional, através de uma ferramenta com fundo educacional com estrutura interativa, Scratch, com público alvo em crianças do ensino fundamental. Para isto, é utilizado o sistema BCI (Brain Computer Interface), uma interface entre o cérebro e o computador, através da qual são mapeados processos e estados mentais. Além disso, utilizar-se-á a ferramenta ActicHamp, um amplificador de canal ativo com canais auxiliares usados para uma gama completa sensores de Biosinais. Também será utilizado o OpenVibe, que permite projetar, testar e utilizar sistemas BCI, para fazer a coleta de dados pré e pós aprendizado. A base teórica se embasa em pesquisas das: neurociências, educação, aprendizado e tecnologia. $\mathrm{O}$ estudo foi realizada em um grupo de alunos do ensino fundamental em que foi possível concluir que o pensamento computacional ocasiona alterações fisiológicas no cérebro de estudantes das séries finais do ensino fundamental de uma escola pública, com intuito de melhora na resolução de problemas.
\end{abstract}

Palavras-Chave: Aprendizado; Educação; Neurociências; Tecnologia.

\begin{abstract}
It is of relevance to research about computational thinking and its possible physiological changes in the brains of elementary school students. This paper presents a part of the data collected from a research that aims to identify areas of the brain that are activated before and after a course of learning of computational logic through an educational background tool with interactive structure, called Scratch, with target audience in primary school children. For this, the BCI (Brain Computer Interface) system is used, an interface between the brain and the computer, through which processes and mental states are mapped. In addition, the ActicHamp tool, an active channel amplifier with auxiliary channels used for a full range of Biosynthetic sensors, will be used. OpenVibe will also be used to design, test and use BCI systems to collect pre and post learning data. The theoretical basis is based on researches of the neurosciences, education, learning and technology. The study was carried out in a group of primary school students, and it was possible to conclude that computational thinking causes physiological changes in the brains of students in the final grades of elementary school in a public school, with the purpose of improving problem solving.
\end{abstract}

Key words: Education; Learning; Neurosciences; Technology. 


\section{Introdução}

Estudar questões de tecnologia e ensino tem se tornado imprescindível para ampliação e manutenção de técnicas que possam favorecer um aprendizado e desenvolver o raciocínio lógico a partir da inserção das ferramentas digitais. A pesquisa que segue tem como objetivo otimizar e desenvolver essa habilidade, com intuito de resolver os problemas de forma mais eficaz. Segundo Consenza and Guerra (2011), quanto mais jovem o indivíduo tiver o entendimento da lógica, melhor seu cérebro trabalhará com as questões do dia a dia. Nas crianças a capacidade de criação de novas sinapses é enorme, por isso deve-se incentivar o ensino da lógica nos primeiros anos de aprendizagem escolar. Assim, os lobos do córtex cerebral têm inúmeras funções no processamento neural. Os principais sistemas identificáveis localizam-se em cada lobo, porém os sistemas do cérebro também cruzam diferentes lobos, ou seja, estes sistemas cerebrais não são mapeados de forma correspondente nos lobos onde primeiramente residem, mas, em parte, as subdivisões anatômicas gerais do córtex cerebral podem ser realizadas a diferentes funções sensório-motoras (Lent; 2010). Por este motivo, o entendimento de neurociência é de enorme importância. Isso porque, ao entendermos o funcionamento do cérebro frente as inúmeras possibilidades de resolução de problemas, podemos determinar qual a melhor forma de ensino, e assim otimizar cada vez mais tais situações. Existe um grande incentivo para o ensino de programação bem como para o aprendizado através de jogos e de materiais que utilizam técnicas dos jogos. Dessa maneira, o ensino da programação nas escolas estimula sua criatividade e ajuda na sua capacidade de lidar com problemas, já que coloca em prática uma série de teorias que são ensinadas em física, matemática e química e lhes possibilita pôr em prática suas ideias, transformá-las em produtos. Ao se pesquisar sobre ferramentas um dos programas mais descritos para aprender através de programação lúdica é a ferramenta Scratch. Ela foi desenvolvida com intuito de estimular a aprendizagem da programação de forma intuitiva através da montagem dos blocos de comandos. Através deste programa, é possível resolver problemas por meio da criação de jogos, animações e de histórias interativas. Assim, aprender a programar é uma das novas habilidades importantes para crianças e jovens num mundo digital, que lhes permite executar os projetos que planejam, torná-los visíveis e desenvolver novas formas de produção. Segundo Moran (2019), "As competências digitais mais importantes hoje, além de programar, são: saber pesquisar, avaliar as múltiplas informações, comunicar-se, fazer sínteses, compartilhar online" . Entre os pesquisadores que têm se dedicado na área de neurociências e educação, é importante salientar, Nascimento (2015), que em seu estudo demonstra a importância da inclusão do ensino de lógica computacional na grade curricular das escolas, e ratifica a utilização do Scratch como uma das maiores ferramentas de apoio. E, também, Bastos (2017), que nos traz uma visão de captura de sinais cerebrais através do eletroencefalograma, e a partir destes, fazer uma análise sem que haja a necessidade de nenhum movimento muscular do sujeito pesquisado. Este trabalho pretende averiguar se o pensamento computacional pode ocasionar alterações fisiológicas no cérebro de estudantes do ensino fundamental. Isso será realizado através de coletas de sinais cerebrais.

\section{Aprendizagem e neurociências}

A evolução e novas evidências na área das neurociências ligada ao processo de aprendizagem é apontada como uma revolução para o meio educacional. As Neurociências da aprendizagem é o estudo de como o cérebro aprende, assim consiste no entendimento de como as redes neurais são interligadas no instante da aprendizagem, bem como a forma como os estímulos acontecem no cérebro, por exemplo: a maneira como as memórias se consolidam, e como acessam-se as informações guardadas (Mietto; 2019).

Compreender-se, então, que a utilização de estratégias adequadas em um processo de ensino dinâmico e agradável provocará, por conseguinte, mudanças no número e na qualidade das conexões sinápticas. Além disso, influenciará no funcionamento cerebral de forma positiva, e permanente (Mietto; 2019).

As Neurociências trazem fatores primordiais a serem desvendados, a fim de otimizar o conhecimento, para aprender de uma maneira mais qualificada, e também se compreender como o ser humano assimila o ensino. Isso nos remete não apenas a como as pessoas aprendem, mas como são ensinadas, um processo de troca. Uma proposta que está numa crescente é a intersecção e a transição entre a educação e a neurociências, denominada neuroeducação, que tem como objetivo promover o encontro do cérebro, da mente e da educação (Oliveira; 2015).

O desenvolvimento de pesquisas integradas nas neurociências têm obtido cada vez mais adeptos. Este interliga, pedagogia, psicologia, a neurologia e outras áreas, que tem como base a tecnologia e a educação. Tal acontecimento, possivelmente será o campo que alterará o paradigma do processo de ensino-aprendizagem e, para que isso aconteça, é de suma importância a continuidade de programas de pesquisa na área, com intuito de entender como as neurociências afetará as profissões (Oliveira; 2015).

No que tange a neurociências, é de suma importância a investigação dos processos, que estudam como o cérebro aprende, lembra e executa tarefas. Para isso, é essencial que a neuroeducação esteja presente na escola, desde a formação do professor, de modo que se possa repassar o conhecimento para os alunos. Assim, a sociedade conseguirá entender de uma forma mais clara as diferenças no processo de aprendizado (Oliveira; 2015).

Compreender como os indivíduos aprendem não é um desafio recente para a educação. As neurociências se une à educação com o objetivo de encontrar respostas, a partir da neuroeducação, um campo de pesquisa educacional, com metodologia própria, que se afirma com o auxílio das neurociências, tecnologia, psicologia e pedagogia (Oliveira; 2015).

As pesquisas mais recentes sobre a mente, 
o cérebro e os processos neurais implicados no pensamento e na aprendizagem são as alternativas mais usadas para obter explicações e um melhor entendimento da ciência da educação. As averiguações multidisciplinares e interdisciplinares com a participação da ciência têm por objetivo abrir o caminho que poderá encaminhar o estudo educacional para a sala de aula (Oliveira; 2015).

Nas neurociências existem meios para confirmar os inúmeros princípios da aprendizagem através de pesquisas. Estudos mostram como o ato de aprender altera a estrutura cerebral e o seu funcionamento. Assim, o saber não é somente mais a capacidade de memorizar informações, mas também a possibilidade de reaver e utilizar as informações corretas em diversos contextos (Oliveira; 2015).

As crianças já sabem lidar com ferramentas tecnológicas com maior facilidade que muitos adultos, pois é uma realidade que foi inserida em seu contexto de aprendizagem para um convívio social desde muito cedo. Elas têm facilidade para aprender a manusear esses objetos, porém, seria relevante que o ensino utilizasse-os como aparato estimulador/facilitador/meio para o desenvolvimento de habilidades (Morin; 2009).

Tendo em vista que cada vez há uma maior necessidade de pessoas com conhecimento tecnológico, é importante que se aprenda cada vez mais cedo conhecimentos referentes à área. $\mathrm{O}$ mundo está cada vez mais voltado para a tecnologia, a fim de facilitar e otimizar processos e resolver problemas. Com este fato, é de extrema importância voltarmos os olhos para as crianças, que são os novos usuários, e futuros desenvolvedores. Conseguimos observar a evolução do processo tecnológico, quando notamos que a curva de aprendizado é menor para as crianças, tal facilidade em manipular dispositivos eletrônicos nos traz um novo prisma, em que elas possam vivenciar e aprender a lógica por trás de tudo (Moran; 2019).

O pensamento computacional tem sido estimulada em diversos países, tais como Estados Unidos, Alemanha e Finlândia, para que seus jovens inovem, e estejam mais preparados para o mercado de trabalho. Defensores de tal ideia ainda acrescentam, que o desenvolvimento desta habilidade auxilia a resolver problemas do cotidiano, incentiva o trabalho em equipe e aumenta a capacidade de pensar de forma sistematizada e criativa (Martins; 2012).

Com tantas tecnologias à nossa disposição, necessitamos desenvolver atividades que nos auxiliem a entender o seu funcionamento, e reconhecer o seu potencial. Em razão disso, é primordial explorar suas vantagens, sobretudo em possibilitar às crianças a experiências de autodescoberta em prol do desenvolvimento do raciocínio lógico, e da liberação da criatividade (Morin; 2003).

Por este motivo, é fundamental estimular os processos criativos na aprendizagem através das tecnologias disponíveis na escola, especialmente a partir do reconhecimento de que ambas fazem parte, constantemente, na vida humana, e sua imbricação pode ser fator determinante para o desenvolvimento dos indivíduos (Martins; 2012).

Para que isto ocorra dentro das instituições ensino, Morin $(2003,2009)$ defende que é preciso mudar a

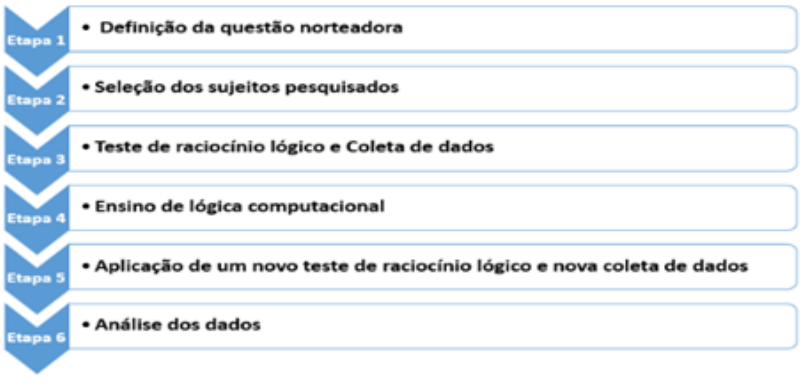

Figura 1: Etapas da Metodologia

forma de ensinar para que seja possível enfrentar os atuais desafios do mundo. Ele critica a fragmentação do conhecimento em disciplinas e a falta de conexão do aprendizado com a realidade.

É necessário, segundo Morin, refletir acerca de mudanças no ensino para que crianças e jovens possam enfrentar os atuais desafios do mundo. Mas, para isso, necessita-se de uma reformulação no ensino, que dê enfoque à interação com a comunidade. Parte-se dos princípios de motivar os educadores a aprender a lidar com a criatividade, com as incertezas, com as conexões múltiplas do ensino com o mundo (Morin; 2003, 2009).

Atualmente, é relevante considerar as últimas investigações que estimulam a conexão do conhecimento específico com as questões neurológicas ou do meio ambiente. Porém, de forma geral, o pensamento computacional é bastante longe da realidade dos jovens e das crianças.

Na busca por um novo modelo para a Educação, Morin trata, em todos os seus trabalhos, da questão da complexidade ou do pensamento complexo. Porém, foi com o advento da cibernética e da teoria da informação que o tema tornou-se objeto de estudo do autor, reunindo o empírico, o lógico e o racional. Por este motivo, a pensamento computacional tem sido inserida em diversos contextos educacionais (Morin; 2003, 2009).

\section{Metodologia}

Foram realizadas diversas etapas para que se alcançasse o objetivo final da pesquisa. Neste artigo, será apresentada uma porcentagem dos dados coletadas para a averiguação final da pesquisa, visto a limitação de espaço, a qual já permite que se traga conclusões muito relevantes para a área. Esses caminhos serão detalhados de modo que se especifique as minúcias do passo a passo, apresentados na Figura 1.

Etapa 1 - Nesta problemática, refletiu-se sobre a questão da importância de analisar se o pensamento computacional gera mudanças fisiológicas no cérebro de estudantes do ensino fundamental; Etapa 2 Nesta etapa, foram escolhidos os alunos do ensino fundamental de uma escola pública da cidade do Rio Grande para participar da pesquisa. São estudantes das séries finais do ensino fundamental, ambos com 11 anos e cursam o sétimo ano. Estes alunos participaram ativamente das duas fases do processo, de modo a propiciar a coleta dos dados necessários para a comparação solicitada na pesquisa. Etapa 


\begin{tabular}{|l|l|l|}
\cline { 2 - 3 } \multicolumn{1}{l|}{} & Função proprietária & Area cerebral a ser ativada \\
\hline Q1 & $\begin{array}{l}\text { Recurso cognitivo, visualizaçăo de } \\
\text { imagens }\end{array}$ & $\begin{array}{l}\text { Lobo Frontal, Lobo Occipital Direito e } \\
\text { Esquerdo }\end{array}$ \\
\hline Q2 & $\begin{array}{l}\text { Representaçōes espaciais, visualização } \\
\text { de imagens, } \\
\text { Recurso cognitivo }\end{array}$ & $\begin{array}{l}\text { Lobo Parietal Direito e Esquerdo,Lobo } \\
\text { Occipital Direito e Esquerdo e } \\
\text { Lobo Frontal }\end{array}$ \\
\hline Q3 & $\begin{array}{l}\text { Representações espaciais, recurso } \\
\text { cognitivo }\end{array}$ & $\begin{array}{l}\text { Lobo Parietal Direito e Esquerdo, Lobo } \\
\text { Frontal }\end{array}$ \\
\hline
\end{tabular}

Figura 2: Funções proprietárias e possíveis áreas cerebrais ativadas em cada questão

3 - Teste de raciocínio lógico e Coleta de dados: Antes de iniciar a coleta de sinais cerebrais, pediu-se autorização ao Comitê de Ética em Pesquisa na Área da Saúde (CEPAS) da Universidade Federal do Rio Grande, para verificar se estavam de acordo com os padrões científicos da investigação, e obtivemos sua aprovação, conforme CAAE: 45606915.8.0000.5324. Feito isso, pode ser coletado os sinais cerebrais dos alunos, enquanto aplicou-se o teste de raciocínio lógico. A ferramenta de captação foi o ArtiCHamp, que é um sistema de ampliação modular, que integra componentes eletrofisiológicos, tais como EEG, BCI, dentre outros. Na Figura 2 apresenta quais funções e áreas cerebrais cada exercício proposto deve estimular. Q1, Q2 e Q3 referem-se às questões resolvidas pelos alunos durante o processo de coleta. Ao lado, sequencialmente, são especificadas as funções proprietárias de cada questão bem como a área do cérebro ativada durante o processo.

Etapa 4 - Ensino de lógica computacional: Neste momento, foi desenvolvido o ensino de lógica computacional através da ferramenta Scratch. Etapa 5 - Aplicação de um novo teste de raciocínio lógico e nova coleta de dados: Após o aprendizado, é de suma importância a aplicação de um novo teste de coeficiência, com o mesmo nível de dificuldade para verificar as áreas do cérebro que foram acionadas durante o processo; Etapa 6 - Análise dos dados: Após conclusão de todos os processos, é fundamental a comparação e análise dos dados previamente coletados. Desta maneira, é possível verificar se houve mudanças fisiológicas no cérebro das crianças que participaram do processo.

\section{Análise pré-capacitação e pós- capacitação dos sujeitos pesquisados}

Conforme visto anteriormente, nas etapas de 2 a 5 da metodologia, realizou-se a obtenção dos dados. Já na etapa 6, analisou-se os dados coletados, com objetivo de encontrar diferenças entre as imagens capturadas através da ferramenta Actichamp, e analisadas através do OpenVibe. Além disso, aplicouse testes de lógica antes e depois do aprendizado. Tanto para a captura, quanto para gerar as imagens 2D e 3D, dois autômatos foram desenvolvidos. Esses foram feitos na ferramenta Openvibe, por meio de blocos pré-existentes. A visualização das áreas ativadas ou não, são construídas a partir da variação de cores (Figura 3). O azul é centro da escala, e quanto mais a cor amarela predominar, mais ativa estará a área cerebral. Por outro lado, quanto mais se

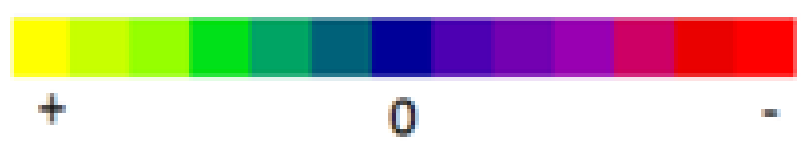

Figura 3: Escala de ativação

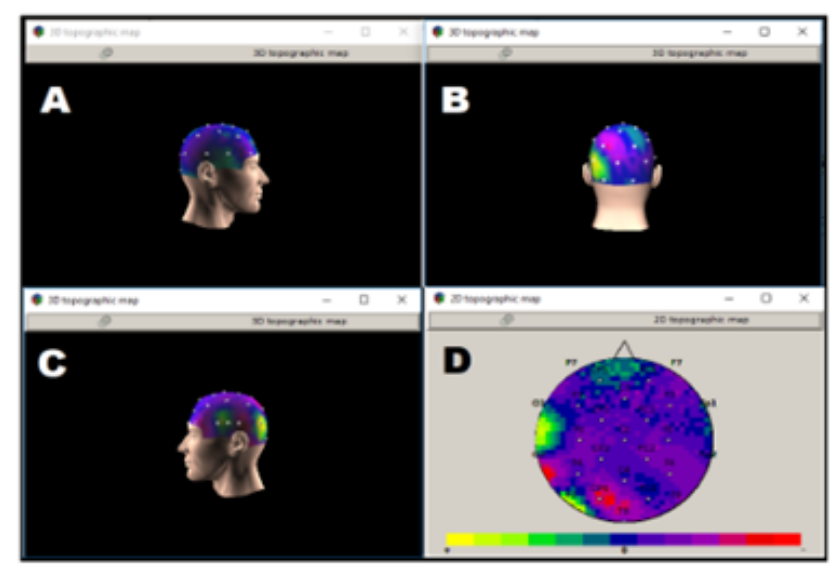

Figura 4: Visualização das imagens 2D e 3D, na primeira questão, pré-capacitação

aproximar da tonalidade vermelha, menor será sua ativação.

É importante salientar que, por motivo de espaço, este artigo apresenta a análise de dois sujeitos. Ambos possuem 11 anos de idade, estão no sétimo ano do ensino fundamental, e são destros.

\subsection{Primeiro sujeito pesquisado}

As imagens subsequentes foram captadas utilizando as atividades cerebrais avivadas a partir da resolução dos exercícios, e foram geradas utilizando a ferramenta OpenVibe. As Figuras 4, 5, 6, 7, 8 e 9 correspondem a um conjunto de imagens, sendo $A$, B e C, de visualização $3 \mathrm{D}$, e a $\mathrm{D}$ de visualização $2 \mathrm{D}$, todas retiradas através da ferramenta OpenVibe. Nelas são demonstradas as atividades do cérebro no momento da resolução do primeiro, dos três exercícios propostos. Será usada como referência a escala de ativação mencionada anteriormente na Figura 3.

Na Figura 4, a Imagem A mostra que o nível de atividades cerebrais são quase nulas. Já na $B$, que é a parte de trás da cabeça, percebe-se a ativação do lobo occipital do lado esquerdo, o qual é associado à área da visão. No que se refere à Figura $\mathrm{C}$, esta diz respeito à parte esquerda da cabeça, e mostra uma maior ativação do lobo temporal, que está relacionado a um grande número de funções distintas, que inclui percepção auditiva, memória a longo prazo e respostas emocionais. Por fim, a D é uma visão periférica da cabeça, onde é possível analisar, de uma maneira geral, quase toda a extensão, na qual verificamos a ativação parcial do lobo frontal.

A Figura 5 compete às imagens das áreas cerebrais ativadas a partir do segundo exercício proposto. Imagem A representa o lado direito da cabeça do sujeito em análise, e não representa praticamente nenhuma ativação. Já a $\mathrm{B}$, é a parte de trás da cabeça, 


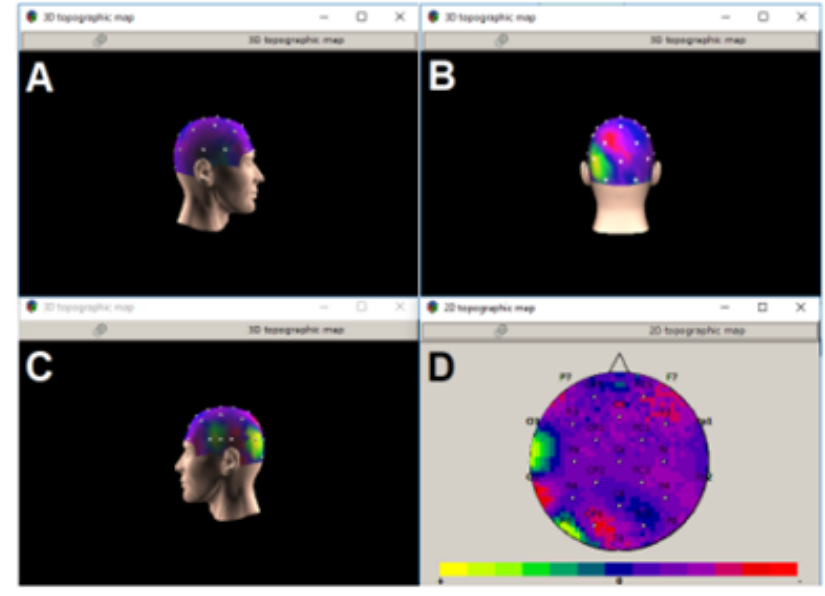

Figura 5: Visualização das imagens 2D e 3D, na segunda questão, pré-capacitação

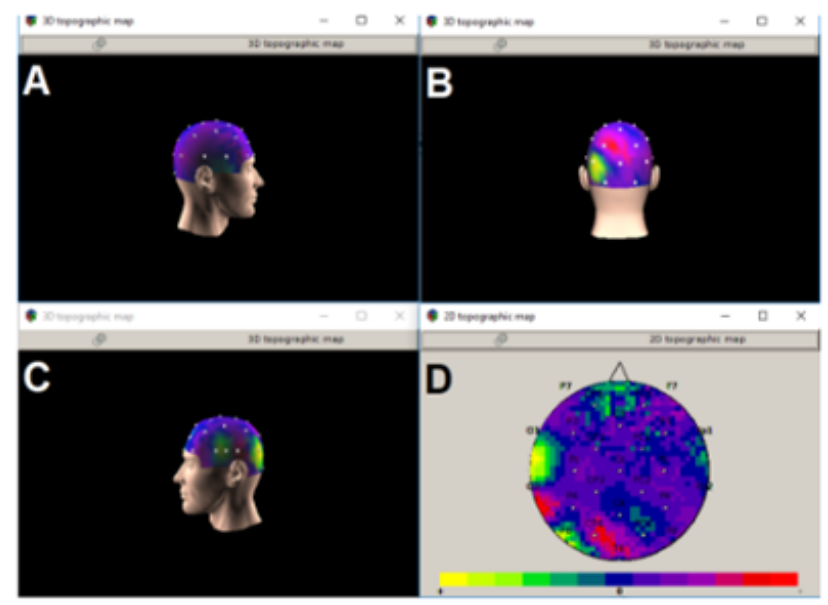

Figura 6: Visualização das imagens 2D e 3D, na terceira questão, pré-capacitação

nota-se a ativação do lobo occipital do lado esquerdo. No que se trata a Figura $\mathrm{C}$, diz respeito a parte esquerda da cabeça, e mostra uma maior ativação do lobo temporal. Por fim, a D é uma visão periférica da cabeça, onde é possível analisar de uma maneira geral quase toda a extensão. E nesta visualização conseguiu-se analisar que não há ativação no lobo frontal.

A Figura 6, reporta-se às imagens das áreas cerebrais ativadas a partir do terceiro exercício proposto. A Imagem A mostra o lado direito da cabeça, e não representa nenhuma ativação. Já a $B$, é a parte de trás da cabeça, nota-se a ativação do lobo occipital do lado esquerdo, no qual retrata a área da visão. Já a Figura $\mathrm{C}$, diz respeito a parte esquerda da cabeça, e mostra uma maior ativação do lobo temporal, que relaciona a um grande número de funções, por exemplo, percepção auditiva, memória a longo prazo, e respostas emocionais. Por fim, a D é uma visão periférica da cabeça, onde é possível verificar de uma maneira geral praticamente toda a extensão. E nesta visualização percebeu-se uma maior ativação no lobo frontal. As imagens que seguem são dos resultados do sujeito pós-capacitação. Serão apresentadas, em seguida, análises detalhadas

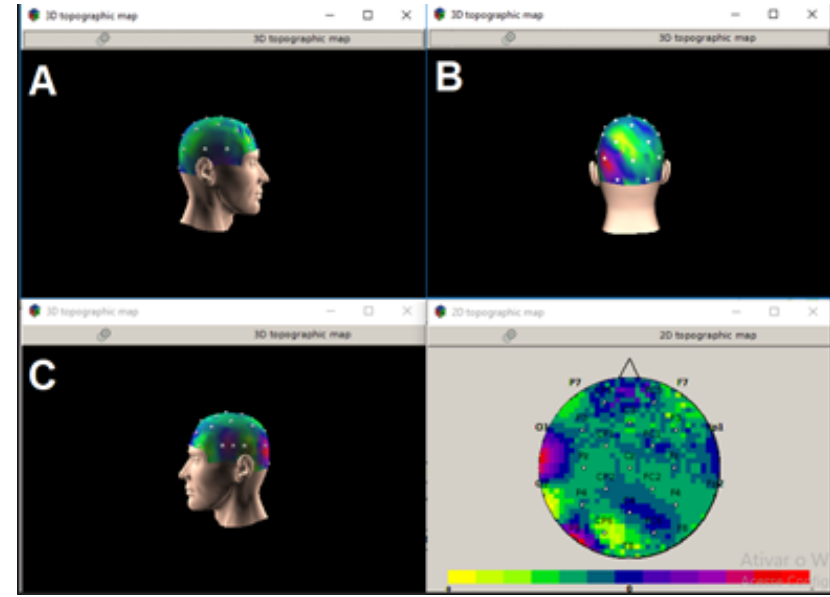

Figura 7: Visualização das imagens 2D e 3D, na primeira questão, pós-capacitação

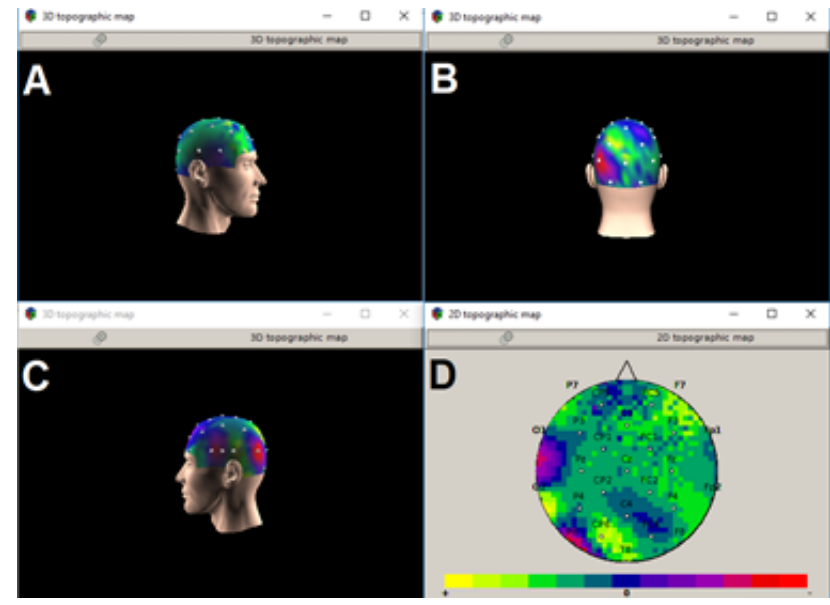

Figura 8: Visualização das imagens 2D e 3D, na segunda questão, pós-capacitação

de cada imagem, conforme foi realizado no processo anterior, pré-capacitação.

A Figura 7 compete às imagens das áreas cerebrais ativadas a partir do primeiro exercício póscapacitação. A Imagem A mostra que o lado direito da cabeça, o lobo temporal, o lobo parietal, e o lobo occipital foram ativados. Já a $\mathrm{B}$ é a parte de trás da cabeça, onde nota-se a ativação do lobo occipital do lado direito. $\mathrm{Na}$ imagem $\mathrm{C}$ analisa-se à parte esquerda da cabeça, e mostra uma maior ativação do lobo temporal e o lobo parietal. Por fim, a D é uma amostra superior da cabeça, na qual, é percebe-se de uma maneira geral o cérebro em funcionamento. Nesta visualização nota-se uma maior ativação no lobo frontal.

A Figura 8, corresponde às imagens das áreas cerebrais ativadas a partir do segundo exercício póscapacitação. Na imagem A verifica-se o lado direito da cabeça, em que foram ativados, o lobo temporal, lobo parietal, e lobo occipital. Já a B é a parte de trás da cabeça, onde pode-se perceber a ativação do lobo occipital do lado direito. A imagem $C$ é a parte esquerda da cabeça, e mostra uma maior ativação do lobo temporal. Na Imagem $\mathrm{C}$, também verificamos a ativação do lobo parietal. A D é uma visão geral da 

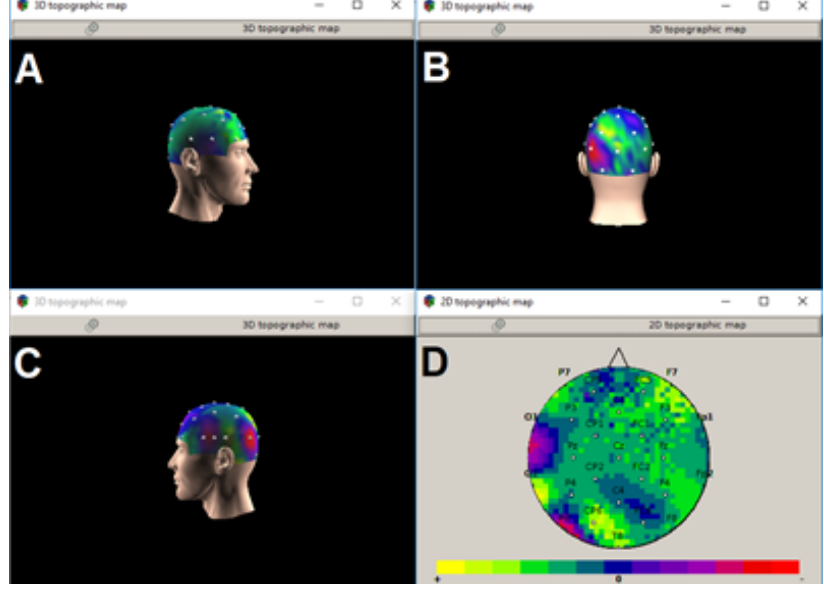

Figura 9: Visualização das imagens 2D e 3D, na terceira questão, pós-capacitação
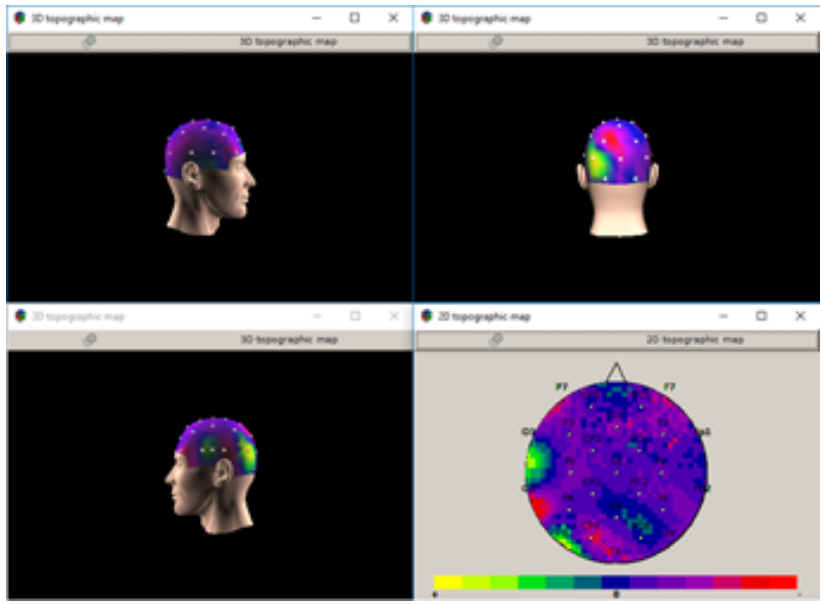

Figura 10: Visualização das imagens 2D e 3D, na primeira questão, pré-capacitação

cabeça e nesta percebeu-se a ativação no lobo frontal.

Por fim, com relação à Figura 9 corresponde às imagens das áreas cerebrais ativadas a partir do terceiro exercício pós-capacitação. Imagem A mostra o lado direito da cabeça do sujeito 1 , foram ativados 0 lobo temporal, o parietal, e lobo occipital. Já a B é a parte de trás da cabeça, em que pode-se perceber a ativação do lobo occipital do lado direito. A Imagem $\mathrm{C}$ mostra uma maior ativação do lobo temporal. Na Imagem $\mathrm{C}$, também verificamos a ativação do lobo parietal. Por último, a D é a parte superior da cabeça e vê-se ativação do lobo frontal.

\subsection{Segundo sujeito pesquisado}

As Figuras 10, 11, 12, 13, 14 e 15 referem-se a um jogo de imagens do sujeito 2 , sendo $A, B$ e $C$, de visualização $3 \mathrm{D}$, e a $\mathrm{D}$ de visualização $2 \mathrm{D}$. Nelas podem ser vistas as atividades cerebrais no momento da resolução dos exercícios.

Conforme é possível observar, na Figura 10, a Imagem A mostra que o nível de atividades cerebrais é quase nula. Já na $\mathrm{B}$, vê-se a ativação do lobo occipital esquerdo, o qual é associado à área da visão. Na $\mathrm{C}$, ativou-se o lobo temporal. Por último, a D percebeu-
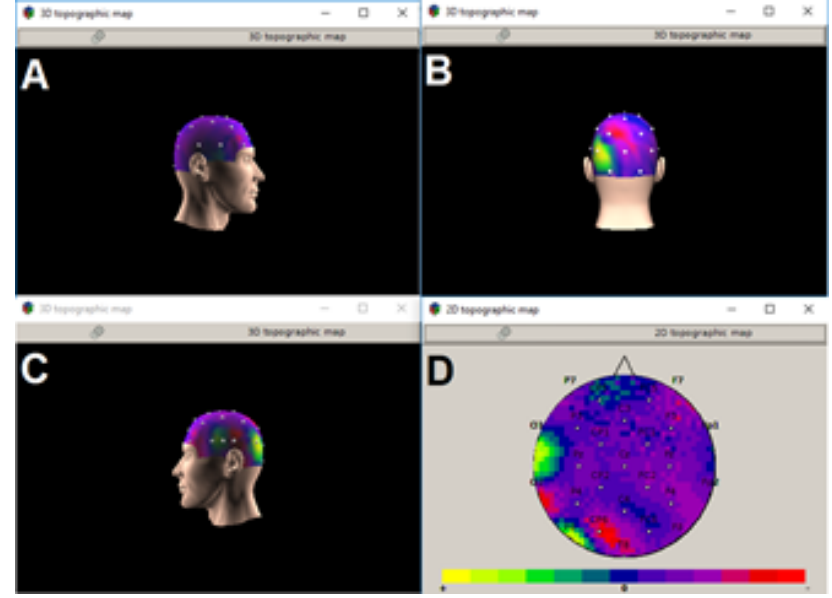

Figura 11: Visualização das imagens 2D e 3D, na segunda questão, pré-capacitação

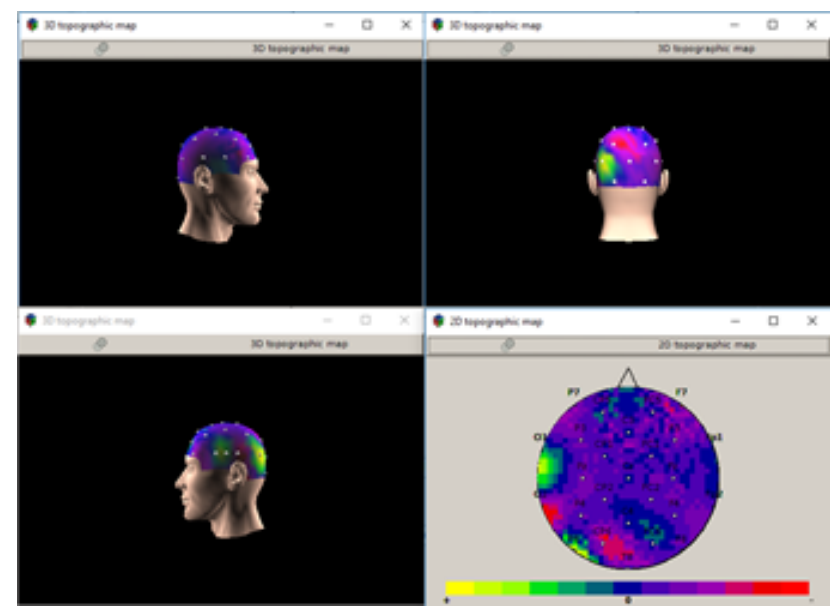

Figura 12: Visualização das imagens 2D e 3D, na terceira questão, pré-capacitação

se, quase toda a extensão, na qual verificamos a falta de estímulos do lobo frontal.

Pode-se analisar, a partir da figura 11, que a imagem A demonstra o nível de atividades cerebrais baixas, aproximando-se da nulidade. A imagem $B$, por sua vez, é o local de trás da cabeça, em que observa-se o avivamento do lobo occipital do lado esquerdo. Já referente à imagem $C$, é a parte esquerda da cabeça, e vê-se uma maior ativação do lobo temporal. Por fim, a imagem D é possível examinar a ativação parcial do lobo frontal de modo holístico.

A questão 3 é representada na Figura 12, na qual a primeira imagem, denominada como A, manifesta as atividades do cérebro do sujeito 2 , referente ao lado direito, e são praticamente negativas. Já a imagem $B$ é a parte posterior da cabeça, e percebe-se que o lobo occipital do lado esquerdo foi ativado. Relacionase a imagem $C$ à esquerda da cabeça, que obteve uma ativação do lobo temporal. Já imagem D é uma visão superior que mostra a ativação parcial do lobo frontal. O sujeito 2, então, passa pelo aprendizado de lógica computacional, junto aos demais, e em seguida, faz o teste novamente. As próximas imagens mostram os resultados do sujeito 2 após a qualificação. 


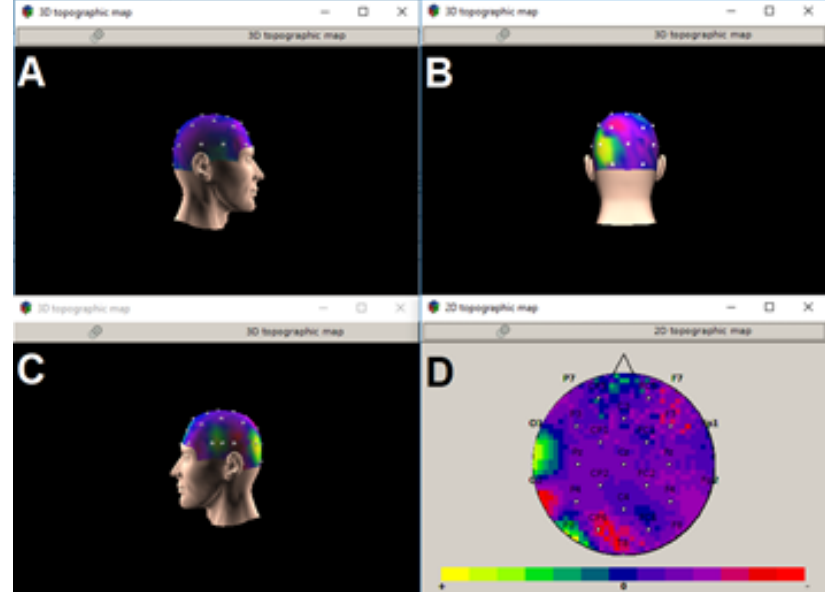

Figura 13: Visualização das imagens 2D e 3D, na primeira questão, pós-capacitação

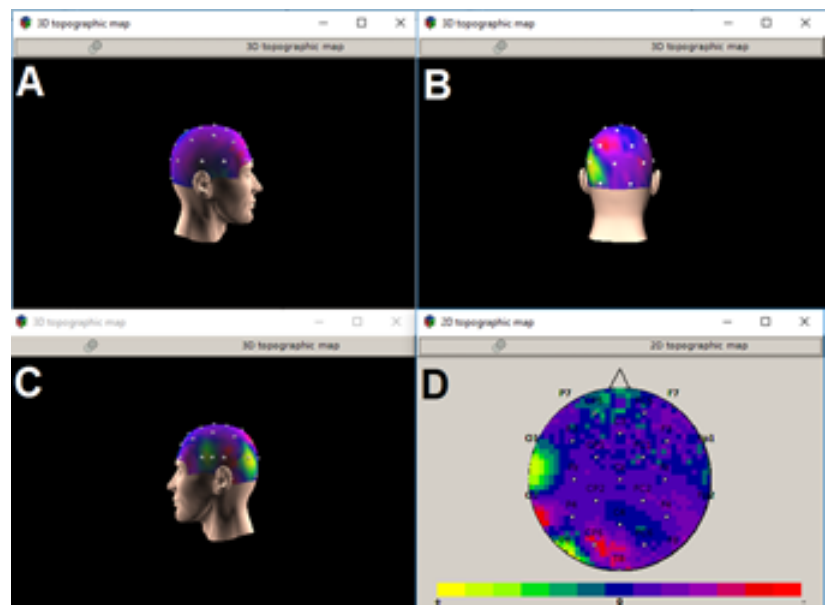

Figura 14: Visualização das imagens 2D e 3D, na segunda questão, pós-capacitação

Continua-se o processo de apresentação e análises discriminadas de cada figura, em conformidade ao processo anterior, a pré-capacitação. A figura a seguir representa o primeiro exercício pós ensinamento de lógica do sujeito 2 . A figura 13 representa o primeiro exercício pós ensinamento de lógica do sujeito 2 .

Como é possível verificar, a figura 14 compete às imagens das áreas cerebrais ativadas através da execução do primeiro exercício após a capacitação do sujeito 2. Inicia-se analisando a imagem $A$, que representa o lado direito da cabeça, em que não apresentou ativação. Por sua vez, a B salienta a parte posterior, em que percebe-se a estimulação do lobo occipital do lado esquerdo, o qual é equivalente à área da visão. Já na imagem $C$, diz respeito a parte esquerda da cabeça, e demonstra uma maior ativação do lobo temporal. Por fim, a D é uma visão superior da cabeça. E, neste ponto, conseguiu-se analisar a ativação do lobo frontal.

As quatro imagens destacadas fazem menção aos lobos estimulados no cérebro do sujeito 2 durante a realização do segundo exercício após a capacitação. As imagens A, B, C e D mostram as diferentes visões do processo. Enquanto a imagem A mostra a fronte direita da cabeça, sem estimulação, a B traz a parte

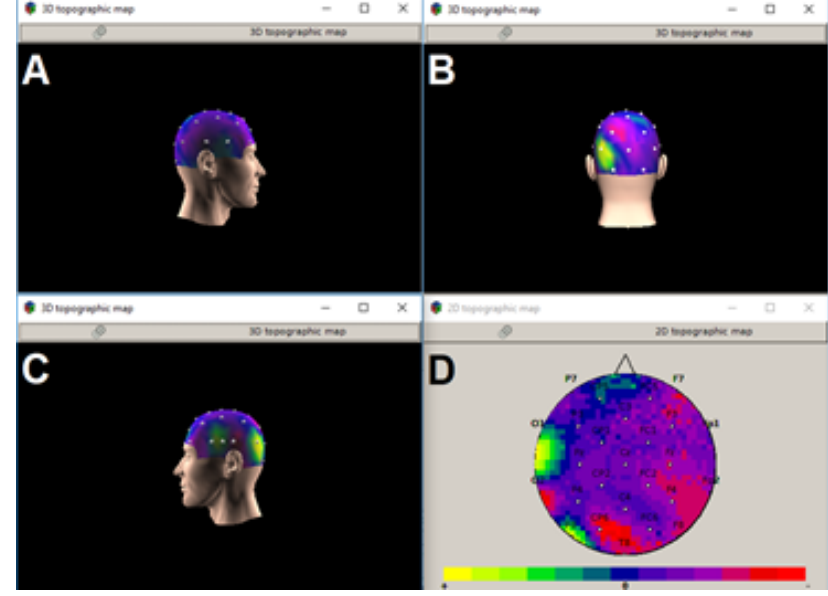

Figura 15: Visualização das imagens 2D e 3D, na terceira questão, pós-capacitação

posterior, com avivamento do lobo occipital do lado esquerdo. A imagem $C$, por sua vez, demonstra que o lobo temporal foi ativado. A D, então, é uma visão superior da cabeça em que foi possível perceber o avivamento do lobo frontal.

A figura 15 compete às imagens das áreas cerebrais ativadas através da execução do terceiro exercício após a capacitação do sujeito 2 . A primeira imagem destacada é a A, que dá enfoque ao lado direito da cabeça, sem ativação neste momento. A imagem B, por sua vez, salienta a parte posterior, em que se percebe a estimulação do lobo occipital do lado esquerdo. A imagem $C$ mostra o lado esquerdo da cabeça, e demonstra uma maior ativação do lobo temporal. A última imagem traz uma visão superior da cabeça, em que obteve-se a ativação do lobo frontal.

\subsection{Comparativo dos resultados obtidos para os dois sujeitos}

Quanto aos resultados dos sinais cerebrais do sujeito 1, pode-se observar que para a questão 1 , após a capacitação, obteve-se o dobro de áreas cerebrais ativadas, entre as quais pode-se perceber 0 avivamento dos novos lobos: temporal do lado direito, parietal do lado direito e esquerdo, e occipital do lado direito, além dos demais já ativados. Nota-se, também, que as funções proprietárias, demonstradas na Tabela 1: o recurso cognitivo e a visualização de imagens, obtiveram resultados ao ativar o lobo frontal e o lobo occipital. Com relação à questão 2 , após a capacitação, percebe-se a ativação de mais quatro áreas cerebrais: lobo frontal, primordial para o raciocínio lógico, lobo temporal direito e esquerdo, responsável pelo gerenciamento da memória humana, e o lobo occipital esquerdo, com função visual. Por fim, observa-se a confirmação das estimulações cerebrais, a partir do resultado observado ao utilizar o exercício 2, comparado com a Figura 2, os lobos: frontal, parietal, occipital, foram ativados. $\mathrm{Na}$ questão 3, por sua vez, constata-se um maior avivamento das áreas cerebrais após a capacitação. Nesta, ativa-se os lobos: temporal direito, parietal direito e esquerdo, e o occipital, além dos ativados na 
primeira coleta. Já em relação à comparação com a Figura 2, constata-se a ativação do lobo parietal, e o lobo frontal, com relação às representações espaciais e dos recursos cognitivos. Já para os resultados dos sinais cerebrais do sujeito 2, pode-se observar que para a questão 1, após a capacitação, o sujeito obteve as mesmas áreas cerebrais ativadas, porém pode-se observar nas imagens, a maior intensidade nestas. Na Figura 2: o recurso cognitivo e a visualização de imagens, obtiveram resultados ao ativar o lobo frontal e o lobo occipital. Na questão 2, após a capacitação, percebe-se a ativação de mais uma área cerebral, o lobo frontal, extremamente importante para resolução de problemas. Por fim, observa-se a confirmação das estimulações cerebrais, a partir do resultado observado, ao utilizar o exercício 2, comparado com a Figura 2, os lobos: frontal, parietal, occipital e frontal. Com relação à última pergunta, concluiu-se que houve uma maior intensidade no avivamento das áreas cerebrais após a capacitação. A Figura 2 mostra a ativação do lobo parietal, e o lobo frontal, com relação a representações espaciais e dos recursos cognitivos.

\section{Conclusão e trabalhos futuros}

Esta pesquisa teve por objetivo verificar se o ensino de lógica computacional ocasiona alterações fisiológicas no cérebro de estudantes do ensino fundamental. Pelos estudos realizados, percebeu-se que essa hipótese é positiva. Essa afirmação é possível, pois foram identificadas as áreas do cérebro ativadas antes e depois de um curso de aprendizado de lógica computacional, usou-se uma ferramenta com intuito educacional, o Scratch. O artigo apresentou dados coletados de 2 sujeitos. Percebeu-se, conforme as imagens puderam ratificar, a diferença entre as áreas cerebrais ativadas durante a pré e a pós capacitação. Tal fator pode acarretar uma melhora na resolução de problemas do cotidiano, e ainda nas disciplinas da escola. Ainda serão necessárias as conclusões das pesquisas com os demais sujeitos, para que se aprofunde as conclusões sobre estes dados. O trabalho foi de grande importância pelo contato com uma escola pública de periferia. Além disso, foi de tamanha relevância a possibilidade dos alunos terem acesso a um curso de lógica computacional, e também permitir que a academia se aproxime ainda mais da realidade da comunidade, trazendo o retorno de suas pesquisas a estes sujeitos. Para trabalhos futuros, pretende-se analisar o número de acertos antes e depois da capacitação, e também adicionar um grupo de controle para melhor averiguar as alterações fisiológicas no cérebro. A Figura 16 traz um resumo das conclusões acerca das áreas ativadas no momento em que este os sujeitos solucionam cada uma das 3 questões propostas, conforme mencionado na metodologia.

\section{Referências}

Bastos, N. (2017). Metodologia para análise eeg utilizando Árvores de decisão: um estudo de caso para reconhecimento de objetos espaciais, Master's thesis, Programa de Pós-graduação em Computação da

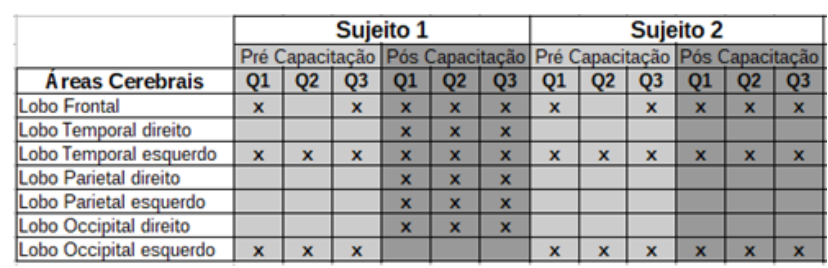

Figura 16: Áreas cerebrais ativadas nas coletas pré e pós capacitações em pensamento computacional

Universidade Federal do Rio Grande.

Consenza, R. M. and Guerra, L. B. (2011). Neurociência na Educação, ArtMed, Porto Alegre.

Lent, R. (2010). Cem bilhões de neurônios? Conceitos fundamentais de Neurociência, Atheneu, São Paulo.

Martins, A. R. Q. (2012). Usando o scratch para potencializar o pensamento criativo em crianças do ensino fundamental. Dissertação de mestrado em Computação Aplicada - Universidade de Passo Fundo.

Mietto, V. L. (2019). A importância da neurociência na educação. só pedagogia. Disponível em: http://www.pedagogia.com.br/artigos/neurocienciaaeducacao> Acesso em: 05 fev. 2019.

Moran, J. (2019). Tecnologias digitais para uma aprendizagem inovadora. Disponível em: <https://moran10.blogspot.com/2017/07/tecnologiasdigitais-para-uma.html> Acesso em: 01 fev. 2019.

Morin, E. (2003). Os sete saberes necessários à educação do futuro, Unesco, Brasília.

Morin, E. (2009). Educação e complexidade: os sete saberes e outros ensaios, Cortez, São Paulo.

Nascimento, C. d. S. (2015). Introdução ao ensino de lógica de programação para crianças do ensino fundamental com a ferramenta scratch. Trabalho de Conclusão de Curso - Universidade Federal de Roraima.

Oliveira, G. G. (2015). A Pedagogia da Neurociência. Ensinando o Cérebro e a Mente, Appris, Curitiba. 